\title{
A decision support methodology to rank projects considering risks and multicriteria analysis
}

\author{
S. F. C. Pinho ${ }^{1} \&$ N. F. F. Ebecken ${ }^{2}$ \\ ${ }^{1}$ BRAZILIAN NAVY, Navy Systems Analysis Center, Brazil \\ ${ }^{2}$ COPPE/UFRJ, Federal University of Rio de Janeiro, Brazil
}

\begin{abstract}
This paper presents a methodology that acts as an instrument to support the decision process of Information Technology (IT) projects prioritization. Data Mining, Multicriteria to Decision Analysis (MDA), Experts Tacit Knowledge Acquisition (KA) and Risk Analysis techniques were used, conjugating thus the knowledge extracted from historical data (database of executed projects), business experts' knowledge and Risk Analysis in accordance with the best practices of Project Management International (PMI).

Hence, starting from a set of candidates, a ranked list of projects is established in a systematic way, stressing the intensity that a project is more qualified then the others. The methodology indicates the aspects that are considered essential for the decision making process, even for the projects which do not have their execution recommended. A case study is presented and some conclusions were commented.
\end{abstract}

Keywords: projects ranking, information technology, data mining, multicriteria decision analysis, risk analysis.

\section{Introduction}

Usually the demand for resources to be allocated in the IT projects is larger than its availability, compelling the organizations to evaluate the priority of each one [1]. 
A methodology for ranking IT projects, besides stressing what is the adequate treatment to be given to each type of project, must solve the allocation conflicts of the resources (material, human or financial).

The presented methodology integrates some potentially useful elements to the support process in ranking IT projects, as presented by a summarized form, in Figure 1.

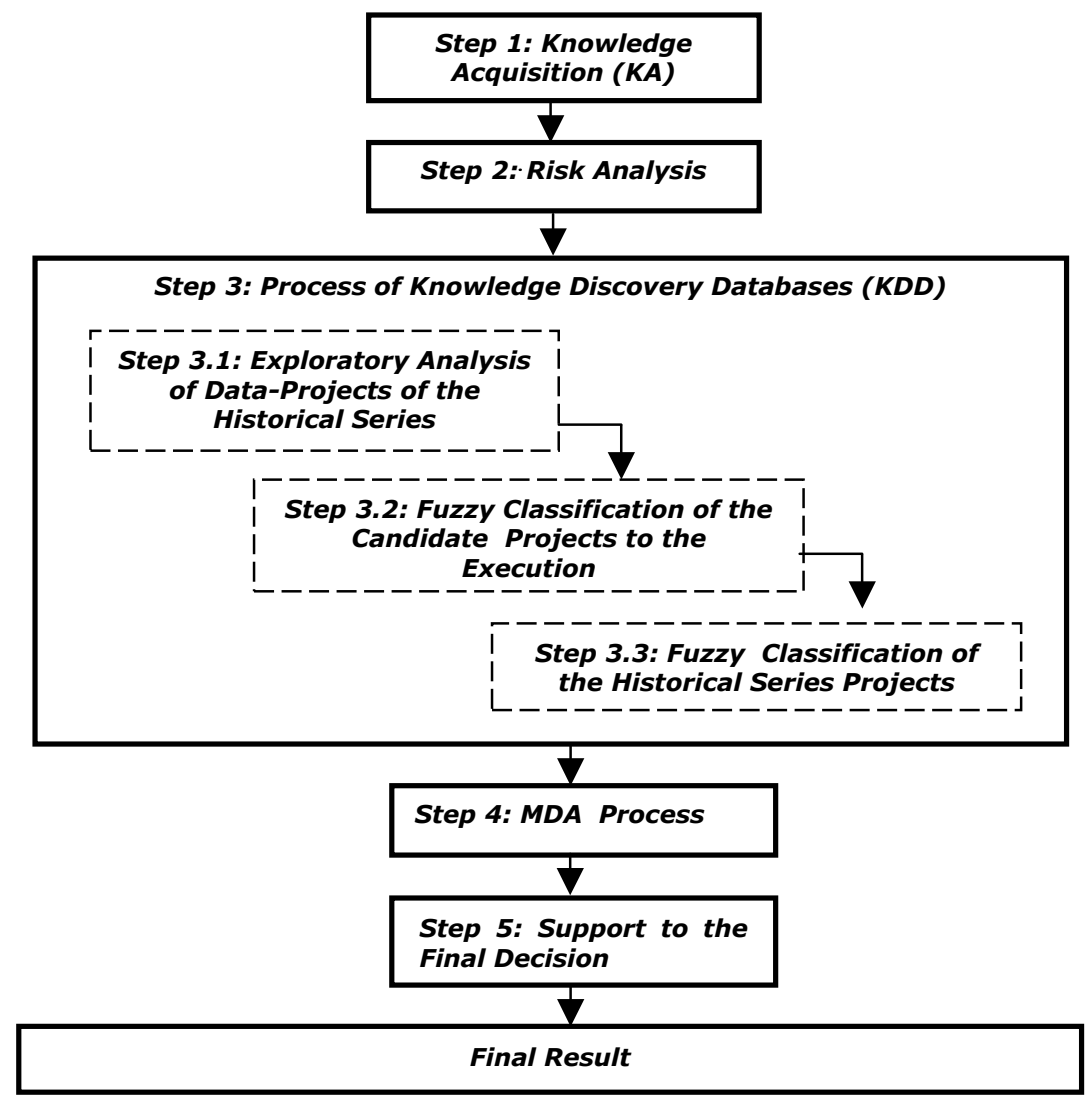

Figure 1: $\quad$ Methodology scheme.

\section{The proposed methodology}

A more detailed description of each step of Methodology for Ranking IT Projects is presented as follows:

Step 1) Knowledge Acquisition (KA):

Process that captures the diversity information and perceptions of the experts group, regarding the set of necessary criteria to evaluate the IT candidate projects to be executed. The candidate projects are the ones that the organization should 
analyze, to establish a priority among them, in order to define an execution order and, even, verify whether the execution is recommended or not.

The result of this step is the criteria set that will be used in Process of MDA to judge each problem alternatives (candidate projects to be executed).

\section{Step 2) Risk Analysis}

In accordance with the best practices of Project Management International (PMI) [9], this process identifies, describes and analyzes the risks of each candidate project. Prepares the Risk Breakdown Structure (RBS) for further categorization and weight attribution to the risks, in order to qualify the risks total impact degree in the project results.

The result of this step is risks total impact degree of each candidate project that will be used in Process of MDA to, together with the criteria set, judge each problem alternatives (candidate projects to be executed).

\section{Step 3) Process of KDD:}

A process accomplished through the three sub-steps as follows:

\section{Step 3.1) Exploratory Analysis of Data - Projects of the Historical Series:}

It aims to extract knowledge, not explicit, of the projects database already executed by the organization (historical series). The obtained result is the classification rules set that will enrich knowledge of experts involved in the problem solution, stressing the behavior standards of successful and unsuccessful projects. It is also performed the selection of the relevant attributes for the formation of a more accurate classifier, that will imply in the discovery of high quality knowledge.

\section{Step 3.2) Fuzzy Classification of the Candidate Projects:}

It establishes for each candidate project (considering the risk total impact degree) in each problem class, from now on denominated: Class 1: successful project and Class 2: unsuccessful project.

\section{Step 3.3) Fuzzy Classification of the Projects of the Historical Series:}

It has the objective to elect a representative for each problem class. The historical project chosen to represent a class will be the one that obtains the highest membership in this class. Each class will be represented by a unique project of the historical series.

\section{Step 4) Multicriteria Decision Analysis Process (MDA):}

A process that will use the criteria set elicited from the experts, together with risks total impact degree, to evaluate each alternative of the problem. At the end, it will be generated a ranked list of the candidate projects, that is, the candidate projects will be ordered from the highest priority up to the minor priority in function of the percentage of priority calculated for each one of them. The priority order indicates the superiority of an option in relation to another. In the ranked list are also ordered, the historical projects that represent each problem class, enabling to analyze the percentage of candidate projects priority regarding the historical projects already executed.

\section{Step 5) Support to the Final Decision:}

Combination of the priority (obtained by the Process of MDA) with the memberships calculated for each candidate project (obtained by the Process of KDD), as described as follows: 
(i) for all the candidate projects and for the historical project representative of Class 1, calculate:

$\%$ of project priority (modified) $=\%$ of project priority calculated * membership of the project in Class 1; and

(ii) for the project representative of Class 2, calculate:

$\%$ of project priority (modified) $=\%$ of project priority calculated * membership of the project in Class 2.

This way, the candidate projects that present low membership in Class 1 of the problem will be penalized, that is, the projects will have their percentage priority decreased.

\section{Computational experiments}

The computational experiment was executed using the historical data of IT projects accomplished at the Naval Systems Analyses Center (CASNAV) [2], military organization of the Brazilian Navy. The criteria used in MDA Process were elicited through the application of questionnaires to the CASNAV experts.

Through the technique of brainstorming with the specialists, we identified a list of risks that could occur during the execution of each project candidate. These risks have been categorized and generated for the Risk Breakdown Structure (RBS) where each was assigned a percentage of probability of a risk and its impact on the project.

To guarantee a degree of desirable generalization to the methodology, the candidate projects belong to another organization that executes similar activities to CASNAV.

It is worth to emphasize that to preserve the confidentiality degree necessary to the organizations projects, the nomenclatures adopted for the projects are fictitious.

\subsubsection{Case study}

The results obtained with the methodology employment will be described as follows:

\section{Step 1) Knowledge Acquisition (KA):}

The questionnaire was the research instrument used to extract tacit knowledge of the experts [3]. The experts are selected in function of the knowledge that each one of them accumulated during their professional life.

The obtained criteria grouped 2 dimensions: Complexity and Strategic Importance, being each one of them composed by the criteria and subcriteria as follows:

(i) Complexity: (i.a) Exequibility: Distributed processing, Updates On-line, Complexity of the Internal Processing, Installation in Different Locations and risks total impact degree; (i.b) Information Availability: Obtained Information from the Customer and Business Rules Definition; and (i.c) Customer Interest: Customer participation and Impact of the System Implantation.

(ii) Strategic Importance: (ii.a) New Opportunities Capturing; (ii.b) Competitiveness Enlargement; and (ii.c) New Technologies Learning. 
That set of criteria will be used by the Method Analytic Hierarchy Process (AHP) Method [4], in order to generate a ranked list of the candidate projects.

\section{Step 2) Risk Analysis}

Identification, description and analysis of the risks of each project candidate. Preparation of Risk Breakdown Structure (RBS) for further categorization and allocation of weight to the risks in order to calculate the full extent of the impact of risks on the project results.

Through the technique of brainstorming were identified risks that may occur during the execution of the projects, as shown in Figure 2.

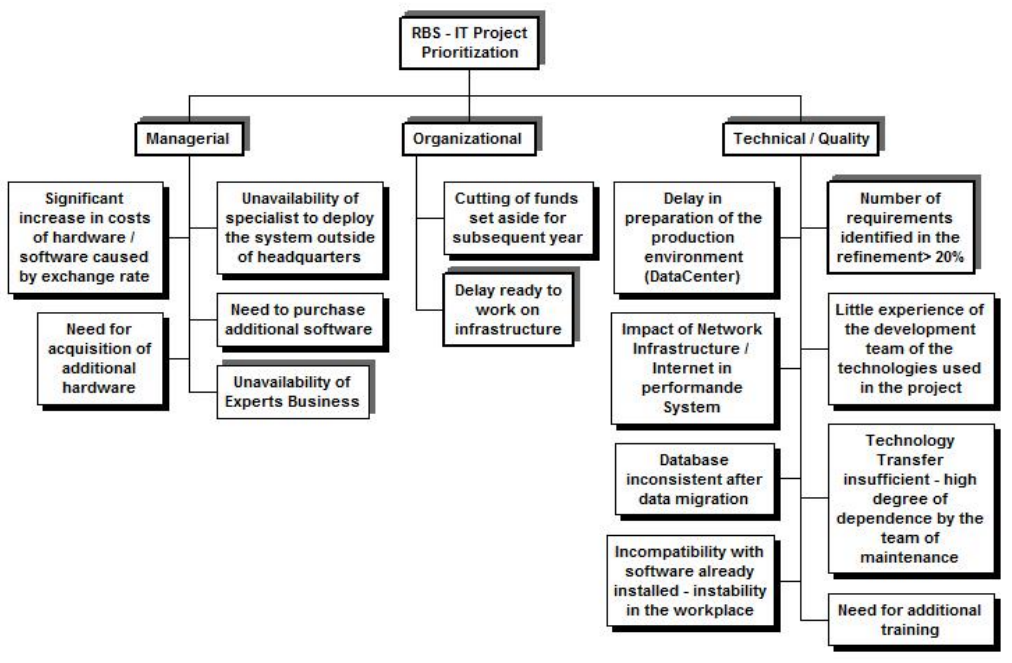

Figure 2: $\quad$ Risk Breakdown Structure (RBS).

The identified risks were qualified as the percentage of probability of occurrence, from 0 to $100 \%$, and about the impact it may have in each project, scale of impact of the risk presented in Table 1.

Table 1: $\quad$ Scale of Impact of Risk.

\begin{tabular}{|l|c|c|c|c|c|}
\hline DEGREE & $\begin{array}{c}\text { Very Low } \\
0,05\end{array}$ & $\begin{array}{c}\text { Low } \\
0,1\end{array}$ & $\begin{array}{c}\text { Moderate } \\
0,2\end{array}$ & $\begin{array}{c}\text { High } \\
0,4\end{array}$ & $\begin{array}{c}\text { Very High } \\
0,8\end{array}$ \\
\hline Cost & $\begin{array}{c}\text { Increased cost } \\
\text { of }>10 \%\end{array}$ & $\begin{array}{c}\text { Increase in Cost } \\
<10 \%\end{array}$ & $\begin{array}{c}\text { Increase in } \\
\text { cost from } \\
10 \% \text { to } 20 \%\end{array}$ & $\begin{array}{c}\text { Increase in cost } \\
\text { of } 20 \% \text { to } 40 \%\end{array}$ & $\begin{array}{c}\text { Increase in } \\
\text { cost }>40 \%\end{array}$ \\
\hline Time & $\begin{array}{c}\text { Increase in } \\
\text { Time }>5 \%\end{array}$ & $\begin{array}{c}\text { Increase in Time } \\
<5 \%\end{array}$ & $\begin{array}{c}\text { Time to } \\
\text { increase from } \\
5 \% \text { to } 10 \%\end{array}$ & $\begin{array}{c}\text { Increase in cost } \\
\text { from } 10 \% \text { to } \\
20 \%\end{array}$ & $\begin{array}{c}\text { Increase of } \\
\text { time }>20 \%\end{array}$ \\
\hline Scope & $\begin{array}{c}\text { Amendment of } \\
\text { requirements of } \\
\text { low complexity }\end{array}$ & $\begin{array}{c}\text { Less important } \\
\text { areas affected } \\
\text { the scope }\end{array}$ & $\begin{array}{c}\text { Important } \\
\text { areas affected } \\
\text { the scope }\end{array}$ & $\begin{array}{c}\text { Reducing the } \\
\text { scope requires } \\
\text { the approval of } \\
\text { the sponsor }\end{array}$ & $\begin{array}{c}\text { Kequirements } \\
\text { not met }\end{array}$ \\
\hline Quality & $\begin{array}{c}\text { Degradation in } \\
\text { quality items of } \\
\text { little importance }\end{array}$ & $\begin{array}{c}\text { Only the most } \\
\text { critical } \\
\text { applications will } \\
\text { be affected }\end{array}$ & $\begin{array}{c}\text { Reduction of } \\
\text { quality requires } \\
\text { the approval of } \\
\text { the Quality } \\
\text { Control Group }\end{array}$ & $\begin{array}{c}\text { Reduction of } \\
\text { unacceptable } \\
\text { quality for the } \\
\text { sponsor }\end{array}$ & $\begin{array}{c}\text { Artifacts } \\
\text { produced non- } \\
\text { compliant }\end{array}$ \\
\hline
\end{tabular}


The result of this step is the risk total impact degree of each project candidate, Table 2, that will be used in Process of MDA to, together with the criteria set, judge each problem alternatives (candidate projects to be executed).

Table 2: $\quad$ Total impact degree of each candidate project.

\begin{tabular}{|c|c|c|c|c|c|c|c|}
\hline Project & $\begin{array}{c}\text { Global } \\
\text { Probability }\end{array}$ & $\begin{array}{c}\text { Global } \\
\text { Impact }\end{array}$ & $\begin{array}{c}\text { risks total } \\
\text { impact } \\
\text { degree }\end{array}$ & Project & $\begin{array}{c}\text { Global } \\
\text { Probability }\end{array}$ & $\begin{array}{c}\text { Global } \\
\text { Impact }\end{array}$ & $\begin{array}{c}\text { risks total } \\
\text { impact } \\
\text { degree }\end{array}$ \\
\hline GE0001 & $60 \%$ & 0,18 & 0,11 & GD0014 & $60 \%$ & 0,12 & 0,07 \\
\hline GD0002 & $80 \%$ & 0,26 & 0,21 & GE0015 & $60 \%$ & 0,18 & 0,11 \\
\hline GA0003 & $90 \%$ & 0,80 & 0,72 & GD0016 & $80 \%$ & 0,26 & 0,21 \\
\hline GD0004 & $70 \%$ & 0,52 & 0,36 & GA0017 & $80 \%$ & 0,70 & 0,56 \\
\hline GE0005 & $40 \%$ & 0,30 & 0,12 & GD0018 & $70 \%$ & 0,52 & 0,36 \\
\hline GD0006 & $90 \%$ & 0,05 & 0,045 & $G E 0019$ & $40 \%$ & 0,30 & 0,12 \\
\hline GD0007 & $75 \%$ & 0,20 & 0,15 & $G E 0020$ & $90 \%$ & 0,05 & 0,045 \\
\hline GA0008 & $65 \%$ & 0,48 & 0,31 & $G A 0021$ & $75 \%$ & 0,20 & 0,15 \\
\hline GA0009 & $90 \%$ & 0,52 & 0,47 & $G D 0022$ & $65 \%$ & 0,48 & 0,31 \\
\hline GD0010 & $60 \%$ & 0,25 & 0,15 & $G A 0023$ & $90 \%$ & 0,52 & 0,47 \\
\hline GD0011 & $80 \%$ & 0,27 & 0,22 & $G D 0024$ & $60 \%$ & 0,25 & 0,15 \\
\hline GA0012 & $70 \%$ & 0,50 & 0,35 & $G D 0025$ & $80 \%$ & 0,27 & 0,22 \\
\hline GA0013 & $85 \%$ & 0,70 & 0,59 & $G E 0026$ & $70 \%$ & 0,50 & 0,35 \\
\hline
\end{tabular}

\section{Step 3) Process of KDD:}

\section{Step 3.1) Exploratory Analysis of Data of the Historical Series:}

A step decomposed onto two activities: a) Classification Rules Extraction and b) Final Selection of the Relevant Attributes.

To accomplish the "Rules Extraction of Classification", the Software CBA was used to extract rules of IT projects historical database classification in 93 records and 27 attributes.

The thirty-seven classification rules were generated initially. That initial set was analyzed with CIAS software (Classification-Rule Interestingness Analysis) in order to generate a consolidated set of interesting, precise and comprehensible rules, resulting in the elimination of the less significant rules [5]. The result of this analysis was the generation of a set of 19 interesting rules. The percentage of support obtained a variation from $22.10 \%$ to $5.82 \%$ (average of $13.81 \%$ ).

Such rules stress the importance of the 22 attributes. This set of attributes will be used by the experts to select the final selection of the relevant attributes.

Each expert with his previous knowledge has the capacity of identifying the attributes that have the interested premise, that is, the ones that strongly guide the IT projects priority.

The 19 attributes selected to compose the final list to be used by the fuzzy classifier are presented as follows:

Final Set of Selected Attributes: Attractiveness, Resource Origin, Updates online, Business Rules Definition, Real Delay of the Project, risks total impact degree, Obtained Information from the Customer, Data Entry on-line, Installation in Different Locations, Priority, Distributed Processing, Type of Project, New Technologies Learning, Complexity of the Internal Processing, 
Impact on the System Implantation, Customer Participation, Performance Importance, Competitiveness Enlargement and Capturing New Opportunities.

\section{Step 3.2: Fuzzy Classification of the Candidate Projects}

Through the fuzzy classification, made with Fuzzy K-NN Method [6], it was calculated the membership of each candidate project to the problem classes, that is, it will be well-known as much as a candidate project belong to Class 1, as well as to Class 2. The 26 (twenty-six) projects and 19 attributes that compose the candidate projects database, were submitted to a categorization and normalization process, resulting in the classification presented in Table 3 .

The membership of each project to the classes, is an important information to be used afterwards, in the Support to the Final Decision.

Table 3: $\quad$ Fuzzy classification of the candidate projects.

\begin{tabular}{|c|c|c|c|c|c|}
\hline Project & $\begin{array}{c}\text { Membership } \\
\text { Class 1 }\end{array}$ & $\begin{array}{c}\text { Membership } \\
\text { Class 2 }\end{array}$ & Project & $\begin{array}{c}\text { Membership } \\
\text { Class 1 }\end{array}$ & $\begin{array}{c}\text { Membership } \\
\text { Class 2 }\end{array}$ \\
\hline GE0001 & 1.00 & 0.00 & GD0014 & 0.06 & 0.94 \\
\hline GD0002 & 0,98 & 0.02 & GE0015 & 0.84 & 0.16 \\
\hline GA0003 & 0.27 & 0.73 & GD0016 & 0.98 & 0.02 \\
\hline GD0004 & 0.87 & 0.13 & GA0017 & 0.40 & 0.60 \\
\hline GE0005 & 0.77 & 0.23 & GD0018 & 0.32 & 0.68 \\
\hline GD0006 & 1.00 & 0.00 & GE0019 & 0.07 & 0.93 \\
\hline GD0007 & 0.62 & 0.38 & GE0020 & 0.25 & 0.75 \\
\hline GA0008 & 0.39 & 0.61 & GA0021 & 0.72 & 0.28 \\
\hline GA0009 & 1.00 & 0.00 & GD0022 & 0.89 & 0.11 \\
\hline GD0010 & 0.78 & 0.22 & GA0023 & 0.73 & 0.27 \\
\hline GD0011 & 1.00 & 0.00 & GD0024 & 0.74 & 0.26 \\
\hline GA0012 & 0.70 & 0.30 & GD0025 & 0.96 & 0.04 \\
\hline GA0013 & 0.55 & 0.45 & GE0026 & 1.00 & 0.00 \\
\hline
\end{tabular}

\section{Step 3.3) Fuzzy Classification of the Historical Series:}

After a categorization and normalization process, the historical series composed by 93 (ninety-three) projects and 19 attributes was analyzed by the Fuzzy K-NN Method, resulting as much each historical project belong to the succeeded projects class (Class 1), and also to the unsuccessful projects class (Class 2). With the fuzzy classification accomplished, the projects that obtained the highest membership in each class were chosen as representatives, as exhibited in Table 4.

Table 4: $\quad$ Elected projects.

\begin{tabular}{|l|c|c|c|}
\hline $\begin{array}{c}\text { Class that } \\
\text { Represents }\end{array}$ & $\begin{array}{c}\text { Elected } \\
\text { Project }\end{array}$ & $\begin{array}{c}\text { Membership } \\
\text { Class 1 }\end{array}$ & $\begin{array}{c}\text { Membership } \\
\text { Class 2 }\end{array}$ \\
\hline Class 1 & 18 & 0.91 & 0.09 \\
\hline Class 2 & 32 & 0.06 & 0.94 \\
\hline
\end{tabular}

The representative historical projects will be used afterwards in the MDA Process, when, together with the candidate projects, they will be submitted to a ranking through the AHP Method .

\section{Step 4) Multicriteria Analysis Process to the Decision (MDA):}

The AHP Method is a method of hierarchical analysis that allows to decompose the problem in hierarchical levels, providing larger easiness to its 
comprehension and evaluation. Thus, the decider is conducted to think in the decision by logic way (hierarchical) and, eventually, evaluate the inconsistency of their judgments . The AHP Method application will be performed through the Tool IPÊ V.1.0 [7] utilization.

To facilitate the judgments of the experts and increase the results analysis power, the set of 26 candidate projects was divided into 5 groups. The denomination adopted for the groups was: Case 1, Case $2 \ldots$ Case $n$.

From this moment, the ranking will be accomplished considering the projects that compose Case 1. The activities of the AHP Method are presented as follows:

(i) CONSTRUCTION OF THE HIERARCHICAL STRUCTURE:

(i.a) Definition of the Main Focus: Ranking 4 candidate projects together with 2 projects of the historical series.

(i.b) Criteria Identification: Using the elicited criteria in the KA step. With the goal of simplifying the process of pair-wise judgment existing in the AHP Method, some criteria were grouped, making the analysis of some of them to be done in a consolidated form.

(i.c) Alternatives: Candidate Projects: GE0001, GD0002, GA0003 and GA0012

Historical Projects: HistClass1 e HistClass2

(ii) DATA ACOUISITION: The pair-wise judgment expresses the degree of preference by an alternative basing itself on the scale suggested by Saaty [8]: equal preference / importance, weak preference / importance, moderated preference / importance or strong preference / importance.

The pair-wise judgment of the alternatives was based on each criterion.

(iii) PRIORITY CALCULATION OF THE ALTERNATIVES: basing itself on data synthesis obtained from pair-wise judgment, it is calculated the priority of each alternative regarding the main focus, for each alternative.

(iv) ANALYSIS OF THE OBTAINED RESULTS

The Consistency Reason (CR) for Case 1 was 0.063 , remaining thus in the standard accepted by the AHP Method $(\mathrm{RC}<=0.1)$.

Ordering, by means of a decreasing form, the calculated priorities for the alternatives of Case 1, are indicated in Table 5.

Table 5: $\quad$ Calculated priority of Case 1.

\begin{tabular}{|c|c|c|}
\hline Order & Project & Calculated Priority (\%) \\
\hline $1^{\circ}$. & GD0002 & 25,08 \\
\hline $2^{\circ}$. & HistClass1 & 25,01 \\
\hline $3^{\circ}$. & GE0001 & 18,37 \\
\hline $4^{\circ}$. & GA0003 & 10,85 \\
\hline $5^{\circ}$. & HistClass2 & 10,66 \\
\hline $6^{\circ}$. & GA0012 & 10,03 \\
\hline
\end{tabular}

Through the analysis of the obtained ranking, it is observed that:

(i) GD0002 candidate project obtained a percentage of superior priority to the historical project that represents Class 1;

(ii) GE0001 and GA0003 obtained an inferior priority in relation to the historical project that represents Class 1 . It also obtained a much higher priority 
in relation to the historical project that represents, positioning itself in the ranking between both problem classes; and

(iii) GA0012 project obtained a priority inferior than the historical project that represents Class 2.

Through this analysis it is possible to observe the superiority of an IT project regarding the others. Until this methodology step, the GD0002, GE0001 and GA0003 projects are recommended, as well as the GA0012 project is not recommended.

In addition to, the following step of the methodology presents a form of make potent the analysis of these results, using the alternative memberships.

\section{Step 5) Support to the Final Decision:}

Table 6 presents the values of the priority percentages and the membership of each candidate project to be used in this step for the calculation of the modified priorities.

Ordering, by means of a decreasing form, the modified priorities for the alternatives of Case 1, are shown in Table 6

After the execution of the $4^{\text {th }}$ methodology step, an alteration in the results occurred. The priority percentage of the GA0003 project, such as GA0012, indicates that the execution of these projects is not recommended, as indicated in Table 7.

Table 6: $\quad$ Priority and memberships.

\begin{tabular}{|c|c|c|c|c|c|}
\hline Project & $\%$ Priority & $\begin{array}{c}\text { Membership } \\
/\end{array}$ & $\begin{array}{c}\% \\
\text { Modified } \\
\text { Priority }\end{array}$ & $\begin{array}{c}\text { Position in the } \\
\text { ranking before } \\
\text { the } \\
\text { modification }\end{array}$ & $\begin{array}{c}\text { Position in } \\
\text { the ranking } \\
\text { after } \\
\text { modification }\end{array}$ \\
\hline GD0002 & 25,08 & $0,98 /$ Class 1 & 24,58 & $1^{\circ}$. & $1^{\circ}$. \\
\hline HistClass1 & 25,01 & $0,91 /$ Class 1 & 22,78 & $2^{\circ}$. & $2^{\circ}$. \\
\hline GE0001 & 18,37 & $1,00 /$ Class 1 & 18,37 & $3^{\circ}$. & $3^{\circ}$. \\
\hline GA0003 & 10,85 & $0,27 /$ Class 1 & 2,93 & $4^{\circ}$. & $6^{\circ}$. \\
\hline HistClass2 & 10,66 & $0,94 /$ Class 2 & 10,02 & $5^{\circ}$. & $4^{\circ}$. \\
\hline GA0012 & 10,03 & $0,70 /$ Class 1 & 7,02 & $6^{\circ}$. & $5^{\circ}$. \\
\hline
\end{tabular}

Table 7: $\quad$ Modified priority.

\begin{tabular}{|c|c|c|}
\hline Order & Project & \% Modified Priority \\
\hline $1^{\circ}$. & GD0002 & 24,58 \\
\hline $2^{\circ}$. & HistClass1 & 22,78 \\
\hline $3^{\circ}$. & GE0001 & 18,37 \\
\hline $4^{\circ}$. & HistClass2 & 10,02 \\
\hline $5^{\circ}$. & GA0012 & 7,02 \\
\hline $6^{\circ}$. & GA0003 & 2,93 \\
\hline \multicolumn{2}{|r}{} \\
\hline
\end{tabular}

\subsection{Obtained results}

After the complete execution of the methodology for Case 1, it is observed that the GA0003 project initially obtained a percentage of priority that, despite being low, did not stress aspects regarding the possibility of an unsuccessful execution. After the accomplishment of the Support to the Final Decision, its positioning in the projects ranking, indicates that its execution is not recommended, by the fact that the percentage of priority was smaller than the percentage of the historical 
project representative of Class 2 . This was possible through the expansion of the analysis using the low membership of the project GA0003 to the class of the successful projects $(0.27)$, membership that has strong influence of the high value in risk analysis conducted for the project (Global Probability: 90\%; Global Impact : 0.80; risks total impact degree: 0.72 ).

Thus, it is possible to conclude that the insert of historical projects in the alternatives list and the modification of the priority percentage provide an analysis enlargement. Through the comparison of the priorities of the candidate projects and the historical projects, it was possible to observe, even in extreme situation, the case in which the indicated candidate project as the most priority, will be able to present a profile of unsuccessful historically project.

\section{Conclusion}

The strong competition, in the current competitive environment, requires that decisions are increasingly accurate and rapid. The adoption of a methodology to effectively support the decision making process for prioritization of IT projects, can be a factor in maintaining the viability and prosperity of the organization. Thus from facts, data and knowledge explicit or implicit, has been shown that it is possible to identify the behavior patterns of IT projects, which tend to be successful, and even emphasize aspects of projects that are not recommended for implementation .

\section{References}

[1] Shimizu, T., Decision in the Organizations: Introduction to the Decision Problems found in the Organizations and Decision Support Systems. $1^{\text {st }}$ ed. Brazil, São Paulo, Atlas, 2001.

[2] Navy Systems Analysis Center. www.casnav.mar.mil.br.

[3] Rezende, S. O., et al., Intelligent Systems: Foundations and Applications.

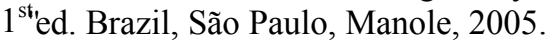

[4] Costa, H.G., Moll, R.N., Use of the Hierarchical Analysis Method (AHP) in the Selection of Varieties for the Plantation of Sugar-cane. Administration and Production, Brazil, São Paulo, November, 1999.

[5] Liu, Bing, Hsu, W., MA, Yiming, Chen, Shu, "Mining Interesting knowledge using DM-II". In: ACM SIGKDD - International Conference on Knowledge Discovery \& Data Mining (KDD-99), San Diego, CA, USA, 1999.

[6] Keller, J. M., Gray, M. R., Givens Jr., et al., “A Fuzzy k-nearest neighbor algorithm", IEEE Transaction on Systems, Man and Cybernetics, v. SMC15, n. 4, pp. 258-260, July/August 1985.

[7] Production Engineering Program of the Federal University Fluminense UFF. www.producao.uff.br

[8] Saaty, T. L., Hierarchical Analysis Method. $1^{\text {st }}$ ed. Brazil, São Paulo, Makron Books of Brazil, 1991.

[9] Project Management Institute, A Guide to the Project Management Body of Knowledge (PMBOK® Guide). 3rd ed, 2004. 